\title{
O QUE CABE NA PANELA? REPRESENTAÇÕES LINGUÍSTICO-DISCURSIVAS EM CONTEXTO POLÍTICO
}

\author{
Eni Abadia Batista (UnB) ${ }^{1}$ \\ Juliana Ferreira Vassolér $(\mathrm{UnB})^{2}$
}

\begin{abstract}
Este artigo apresenta análise de representações visuais como elemento central de intertextualidade nas publicações de revistas midiáticas e discute como os discursos, mesmo que permeados de metáforas, contribuem para a construção de representações sociais e identidades. A metodologia é qualitativa (descritiva e interpretativa) e a análise concentra-se em um corpus constituído por um texto selecionado de publicações veiculadas no mês de maio de 2016, no jornal "ACapa". Trata-se de um jornal cuja característica constitui-se em uma primeira e única página, na qual condensa a notícia em título e imagens. Para o estudo, considera-se como base teórica pressupostos da Análise de Discurso Crítica (ADC), (FAIRCLOUGH, 2003), da Teoria de Atores Sociais (van LEEUWEN, 1997) e da Semiótica Social (KRESS, 2010) e sobre os conceitos de metáfora (LAKOFF; JOHNSON, 2002). Os resultados demonstram que o texto analisado carrega marcas de ideologias que veiculam relações de poder, tanto dos produtores do texto quanto dos receptores. Traz informações que têm consequências materiais, pois mobiliza e faz provocações sociais, além de sugerir uma identificação do leitor com a classe social representada. A identidade, dessa forma, absorve aspectos do contexto e sugere a existência de empoderamento e de consciência política da classe média, embora seja negligenciada. De acordo com os pressupostos da Gramática do Design Visual, o texto expõe uma representação conceitual por meio de uma metáfora visual retratada por uma panela que evidencia atributos e identidades marcadas pelo contexto sociopolítico.

Palavras-chave: representação social; metáfora; discurso; semiótica social.
\end{abstract}

This article presents the analysis of visual representations as a central element of intertextuality in the publications of media magazines and discusses how discourses, even if permeated by metaphors, contribute to the construction of social representations and identities. The methodology is qualitative (descriptive and interpretive) and the analysis focuses on a corpus consisting of a text selected from publications published in May 2016, in the newspaper "ACapa". It is a newspaper whose characteristic is a first and only page, in which it condenses the news in title and images. For the study, the assumptions of the Critical Discourse Analysis (ADC), (FAIRCLOUGH, 2003), the Social Actors Theory (van LEEUWEN, 1997) and the Social Semiotics (KRESS, 2010) and the concepts of metaphor (LAKOFF; JOHNSON, 2002). The results show that the analyzed text carries the marks of ideologies that convey relations of power, both of the producers of the text and the recipients. It brings information that has material consequences, as it mobilizes and makes social provocations, besides suggesting an identification of the reader with the represented social class. Identity, in this way, absorbs aspects of the context and suggests the existence of empowerment and political consciousness of the middle class, even though it is neglected. According to the assumptions of the Grammar of Visual Design, the text exposes a conceptual representation through a visual metaphor portrayed by a pot that shows attributes and identities marked by the sociopolitical context.

Keywords: social representation; metaphors; discourse; social semiotics.

1 Doutora em Linguística pela Universidade de Brasília- UnB, mestre em Educação; especialista em Ensino da Língua Portuguesa; professora assistente substituta do LIP- UnB de 2015 a julho de 2016; professora e tutora do Curso de Letras-EaD-UnB; pesquisadora do CEPADIC; membro e pesquisadora da ALED e do GP Múltiplas Linguagens, Semiótica e Discurso na Contemporaneidade - SDiscon.

${ }^{2}$ Mestranda em Linguística pelo PPGL na Universidade de Brasília, em 2017, especialista em Práticas de Letramento e Práticas Interdisciplinares pela Universidade de Brasília, em 2015; especialista em Língua e Literatura pela UEG, em 2005, desenvolve pesquisas acadêmicas com discursos, representações sociais e textos. 


\section{Introdução}

Não há como negar a afirmação de que as imagens estão cada vez mais presentes nas interações sociais contemporâneas. A escrita não ocupa mais o lugar central na comunicação, no entanto, tornou-se apenas uma parte integrante do texto o qual passou a ser constituído por diferentes modos semióticos e, em colaboração mútua, constroem significados. Essas transformações colocam em evidência o texto multimodal como escolha para as produções dos mais variados níveis.

Segundo Kress e Van Leeuwen (1996, 2006), todos os textos ou produções escritas são sempre materiais com componente multimodal. Assim, para os autores, a escrita é tanto semiótica visual como linguística. Desse modo, enquanto o discurso pode congregar as informações implícitas com os aspectos sociais e com os estados emocionais, é também carregado de significados que são linguisticamente codificados. Nessa perspectiva, as formas de comunicação trazem características que imprimem várias semioses ${ }^{3}$. Um texto multimodal, portanto, que contém palavras e imagens pode ser interpretado, em parte, por meio das categorias criadas pela Gramática Visual (GDV) de Kress e Van Leeuwen (1996, 2006).

A pesquisa com textos multimodais e sobre o modo como os leitores orientam-se em relação a esses textos pressupõe a competência para relacionar significados a contextos sociais particulares e buscar modos alternativos de representação, pois a sociedade contemporânea exige uma nova configuração de práticas textuais.

Nesse contexto, e considerando que o texto multimodal apoia-se em diversos recursos semióticos na elaboração do sentido, este artigo analisa representações visuais como elemento central de significados em publicações midiáticas e discute como os discursos são permeados de metáforas e contribuem para a construção de identidades. Para isso, adota os pressupostos teóricos da Multimodalidade de Kress (2010), da Análise de Discurso Crítica de Fairclough (2003), da Gramática Visual de Kress e van Leeuwen (1996, 2006) e de Metáforas da vida cotidiana, conforme Lakoff e Johnson (2002).

O artigo propõe a análise de publicações do jornal “ACapa”, que se descreve como "um jornal sem jornal” e se classifica como "a primeira página que você não vê no

3 O termo semiose, conforme Fairclough (1996, 2003, 2010), sugere a vantagem de que a análise de discurso está preocupada com várias modalidades semióticas das quais a linguagem é apenas uma. Semiose é entendida, portanto, como um elemento social, uma parte ou um aspecto da vida social. (FAIRCLOUGH, 2010, p. 81). 
jornal que você lê". A distribuição do jornal ocorre somente na internet por meio das redes sociais.

A seleção do corpus seguiu critérios tais como o de ser um texto multimodal, veiculado exclusivamente nas redes sociais de comunicação via Web e o de fazer referência ao movimento político denominado "panelaço”.

Os procedimentos metodológicos que caracterizam o estudo estão fundamentados numa pesquisa de cunho qualitativo para realizar a seleção do corpus e para o desenvolvimento da análise que está concentrada na descrição discursiva dos dados e dos significados dos recursos semióticos. De acordo com Brasileiro (2013, p. 49), “análise discursiva é aquela que se ocupa de interpretação dos fenômenos e da atribuição de significados”, portanto, constitui-se adequada para este estudo.

Em harmonia com a pesquisadora, Neves (1996, p.1) indica a abordagem qualitativa para esse tipo de estudo, pois, segundo o autor, é um tipo de pesquisa que "compreende diferentes técnicas interpretativas que visam descrever e decodificar os componentes de um sistema complexo de significados", além disso, oferece condições para considerar o eixo interpretativo do pesquisador como referencial.

Com base nessas diretrizes, selecionamos um texto do jornal “ACapa”, publicado em maio de 2016, cuja temática traz referências ao movimento social denominado "panelaço" para constituir o corpus do estudo.

\section{Contextualização}

As publicações selecionadas constituem-se como produções discursivas do jornal “ACapa” cujo traço marcante é o uso de metáforas visuais em suas representações sociais. O texto foi produzido no contexto político-social de grande transformação, no qual o processo de julgamento de impeachment da presidente do Brasil, Dilma Rousseff, tramitava na Câmara dos Deputados.

Diante do evento pouco comum, a sociedade civil brasileira articulava-se com manifestações generalizadas de grupos a favor e contra o impeachment em várias cidades. Na Câmara dos Deputados, após votação calorosa, iniciava-se o processo de impeachment que afastou a presidente e, como consequência, o vice-presidente Michel Temer assumiu a presidência até que o Senado, em votação plenária, definisse o impeachment. Paralelamente corria no Superior Tribunal Federal o processo de 
afastamento do Presidente da Câmara, Eduardo Cunha, por ser réu em uma ação penal por envolvimento em corrupção.

\section{Circuito visual discursivo: contribuições teóricas}

Para empreender a análise, algumas proposições teóricas precisam ser demarcadas, como a Teoria Semiótica Social Multimodal, a Gramática do Design Visual, a Análise de Discurso Crítica (ADC) e o conceito de identidades e de metáforas.

Os participantes do processo de comunicação demonstram grande interesse na dinâmica de produção dos significados e elaboram representações cuja interpretação se realiza com base nas experiências sociais e políticas motivadas por contextos diversos.

As representações são elaboradas com base na relação de colaboração entre um conjunto de signos socialmente compartilhados e os diversos modos semióticos. Nesse entendimento, a Semiótica Social, defendida inicialmente por Hodge e Kress (1988) e mais tarde por Kress (2010), expande o preceito para a Teoria Semiótica Social da Multimodalidade (TSSS) e considera os significados socialmente construídos por meio de formas semióticas, de textos e de práticas semióticas de todos os modos que emergem da sociedade, em contextos diversos e em todos os momentos da história humana. É nesse viés que surge a nomenclatura multimodalidade.

Na perspectiva da Teoria Semiótica Social da Multimodalidade (Kress, 2010), os significados são gerados pelo contexto social e organizados em sistemas de representação socialmente estabelecidos. Assim, todos os textos são multimodais e construídos pelas representações discursivas. Nesse processo circular, encontram-se o nível semiótico da representação, que considera o objeto em um dado contexto de situação e de cultura, e o nível semiótico da comunicação, que examina a expressão dos atores sociais em um determinado encadeamento de ideias dentro de certo contexto.

Kress e van Leeuwen (1996) definem representação como um processo no qual o produtor de um signo busca um recurso semiótico que esteja conectado com o seu interesse e com a sua história cultural, social e psicológica, e que esteja focalizado em um contexto específico da produção (KRESS; VAN LEEUWEN, 1996).

Desse modo, a percepção da dimensão social é indispensável para a compreensão e análise dos processos e estruturas das diversas formas de linguagem e de seus sistemas de significado. É nesse sentido que surgem os estudos multimodais.

Acerca do tema, Vieira e Ferraz (2011, p.13) explicam que a multimodalidade compreende a produção de signos e significados como uma "ação social realizada em 
determinado contexto de uso no qual o interesse do produtor determina a forma de representação".

Para as autoras, tanto o estudo do texto como o do discurso deve ser considerado como sistema semiótico multimodal, organizado como produto do contexto social, estabelecido em campo histórico-político e pelas estruturas de poder que revelam aspectos ideológicos.

Assim, pressupõe-se que o analista de discursos seja dotado de certa habilidade para relacionar significados a contextos sociais particulares e para compreender modos alternativos de representação. Para isso, deve-se considerar que a sociedade contemporânea exige nova configuração de práticas textuais e consequentemente implica a busca de competência distinta para a compreensão de metáforas que podem estar submersas nos textos multimodais.

A produção de textos vislumbra uma riqueza no fluxo de recursos disponíveis como imagens, sons, cores e outros modos de estruturação dos textos os quais exigem novas regras de análise, e nesse círculo visual, a leitura multimodal transcende a semiótica clássica. Apoiada em Kress (2010), Batista (2014) escreve que:

a prática de concentrar-se a textualidade nas questões sociais e na sua leitura é princípio básico da Semiótica Social Multimodal bem como da Análise de Discurso Crítica, pois chama a atenção para todas as formas de significação de atividades do meio social, especialmente no campo da política e das estruturas de poder, nas quais há distintos interesses por parte daqueles que produzem textos (BATISTA, 2014, p. 10).

Dessa forma, é possível entender que o ponto central da Teoria Semiótica Social Multimodal é o significado implícito nos recursos utilizados nas produções como processo de construção social, imerso em dinâmicas culturais e ideológicas.

As representações visuais são consideradas ideologicamente motivadas e os discursos são constituídos por vários modos semióticos, enquanto que o estudo e a análise de textos compreendem a perspectiva semiótica que implica a multimodalidade. Nesse sentido para o estudo e análise da imagem, é necessário observar as representações visuais.

Tal como o pensamento de Kress e van Leeuwen (2006) e Kress (2010), para Santaella e Nöth (2014), não há representações visuais que não tenham surgido de imagens na mente daqueles que a produziram, do mesmo modo como não há imagens mentais que não tenham alguma origem no mundo concreto dos objetos visuais. 
Desse modo, a representação pode ser vista como descrição ou como simulação da realidade. A função interpretativa seria a relação do leitor com o contexto, que se configura como sistema social de conceituação, no qual os significados são estabelecidos socialmente, impulsionando a criação de novos ícones e o desenvolvimento de representações que instituem cada vez mais novas metáforas.

Para Lakoff e Johnson (2002), o sistema social de conceituação parte fundamentalmente de recursos utilizados de forma extensa na vida cotidiana e, assim, surgem as metáforas. São construídas por meio de uma imagem mental cujos signos representam o ambiente visual. Os autores explicam que as metáforas não são aleatórias, mas se estabelecem com coerência exteriorizada ao signo e torna-se culturalmente determinada. Assim, a experiência e os valores fundamentais de uma cultura se constituem coerentes com as estruturas das metáforas das quais a sociedade utiliza.

As metáforas para Lakoff e Johnson (2002) classificam-se em: (i) ontológicas, (ii) estruturais, (iii) orientacionais. As metáforas ontológicas nos permitem compreender certas experiências e estabelecer relações entre eventos, atividades, emoções, ideias como entidades e substâncias. Permitem uma grande variedade de propósitos, como referir-se; quantificar; identificar aspectos; identificar causas; traçar objetivos e motivar ações, entre tantos outros. Muitas vezes, nem percebemos esse tipos de construções como metáforas, pois elas estão presentes na nossa vida cotidiana.

As metáforas estruturais, segundo os autores, são necessárias para relacionar conceitos que compreendem a experiência humana. São tão naturais que, usualmente, são tomadas como evidência de um fenômeno de descrição direta. São usadas para compreender eventos, ações, atividades e circunstâncias da condição humana.

No que se refere às metáforas orientacionais, os autores indicam que elas se relacionam com orientação espacial como, por exemplo, em cima, embaixo, dentro, fora, frente, profundo, raso, central, periférico entre outros. Essas orientações espaciais são apresentadas como não motivadas e transcendentes da experiência física e cultural dos atores sociais a quem se referem. São listadas como uma prática discursiva que se naturaliza na vida cotidiana de uma sociedade como, por exemplo, a expressão "para cima” que significa "feliz"; "para baixo" que pode ser uma metáfora para a situação de “tristeza”. Há muitas expressões com significados estabelecidos pelos discursos que permeiam a sociedade, como “consciente" pode estar relacionado a quem está para cima; “inconsciente" a quem está para baixo; cheio de "saúde e vida” pode também 
significar para cima; “doença e morte” pode significar para baixo; “bom”, para cima; "mau”, para baixo, entre outros.

Assim, os conceitos, conforme as descrições, contribuem para o estudo da construção de discursos nos quais a imagem se funde com a representação semiótica, por meio do discurso verbal, estabelecendo metáforas e criando identidades nas relações sociais que são motivadas por ideologias e por manifestações de poder, em conformidade com os estudos de ADC de Fairclough (1996, 2003).

Segundo o Fairclough, uma análise com enfoque nos significados representacionais deve considerar três categorias básicas: os processos, que se referem ao modo como os participantes agem nos eventos sociais; os participantes, que podem ser representados pessoal ou impessoalmente, como agentes ou pacientes, ou ainda, podem ser nomeados de acordo com a classe ou categoria a que pertencem; além das circunstâncias de tempo e lugar. Fairclough (2003) defende que:

Para analisar os textos, sob a perspectiva representacional, é necessário verificar quais processos, participantes e circunstâncias estão incluídos na representação dos eventos observados, quais elementos foram excluídos, aos quais foi dada maior importância; se o evento social está representado de forma concreta ou abstrata e qual é o nível de generalização da representação (FAIRCLOUGH, 2003, p. 135-136).

Diante dessa visão, e aproximando-se das leituras dos processos ideológicos e de poder, a percepção da dimensão de análises, políticas, historicizadas e críticas é uma habilidade que se torna necessária nas sociedades contemporâneas.

A utilização da linguagem na esfera da prática social é determinada por fatores históricos, culturais e das estruturas de poder. Assim, o discurso seleciona e transforma esses elementos de acordo com os interesses do contexto. Portanto, a transformação do discurso depende do conhecimento dos participantes e é realizada por ações específicas baseadas nas referências intimamente ligadas às experiências e práticas sociais.

O discurso não só constitui versões de práticas sociais como legitima ou critica práticas que podem ser contextualizadas. Sob essa perspectiva, Kress e van Leeuwen (2006) definem o discurso como:

Conhecimentos socialmente construídos sobre alguns aspectos da realidade [...] é desenvolvido em contextos específicos nos quais são sempre apropriados aos interesses sociais dos atores, sejam eles externos (Europa Ocidental) ou não (uma família em particular), contextos 
explicitamente institucionalizados (jornais) ou não (conversa informal no jantar) (KRESS; VAN LEEUWEN, 2006, p. 4, tradução livre). ${ }^{4}$

O discurso assim considerado avigora a convicção de que o texto como evento discursivo concebe significados, advindos das maneiras como ele figura em práticas sociais e nos modos de representar, de interagir e de ser. As motivações discursivas são constituídas por meio de elementos representados e das práticas sociais que os legitimam, especificamente no que se refere aos efeitos em lutas hegemônicas.

Sob o entendimento de que o processo de significação faz parte das práticas discursivas e sociais, o campo dos estudos multimodais investiga 0 trabalho intersemiótico entre as modalidades da linguagem, em diálogo com esses significados. Essa perspectiva, assim organizada, traz como ponto central das análises, a ideia de que as estruturas visuais assemelham-se às estruturas linguísticas. A respeito desse aspecto, destaca-se que a organização dialógica tem como base na noção de significado, antes preconizado por Halliday (1994) como função. a) função ideacional; b) função interpessoal; c) função textual. Essas funções foram adaptadas por Kress e van Leeuwen (1996) para os estudos da linguagem visual como: a) metafunção referencial; b) metafunção interpessoal; c) metafunção composicional, respectivamente.

A noção de função e de metafunção da linguagem mais tarde, portanto, foi recontextualizada em Fairclough (2003), enfocando os significados do discurso como significados representacional, identificacional e acional, conforme quadro abaixo:

Quadro1: Relações ente LSF, GDV e ADC

\begin{tabular}{|c|c|c|c|}
\hline \multicolumn{2}{|c|}{ LSF (Halliday, 2004) } & GDV (Kress e van Leeuwen, 1996) & ADC (Fairclough, 2003) \\
\hline Função Ideacional & $\rightarrow$ & Metafunção Referencial & $\rightarrow \begin{array}{l}\text { Significado } \\
\text { Representacional }\end{array}$ \\
\hline Função Interpessoal & $\rightarrow$ & Metafunção Interpessoal & $\rightarrow \begin{array}{l}\text { Significado } \\
\text { Identificacional }\end{array}$ \\
\hline Função Textual & $\rightarrow$ & Metafunção Composicional & $\rightarrow$ Significado Acional \\
\hline
\end{tabular}

Fonte: Adaptação da LSF na GDV e recontextualização na ADC, elaborado pelas autoras.

A equivalência indicada no quadro se pauta no papel que a linguagem desempenha na vida das pessoas como atores, nas necessidades e interesses nos quais ocorrem o processo de significação como parte da constituição das práticas sociais.

\footnotetext{
4 "socially constructed knowledges of (some aspects) of reality [...] developed is specific social contexts and in ways which are appropriate to the interest of social actors in these contexts, whether these are very broad contexts ('Western Europe') or not (a particular family), explicitly institutionalized contexts (newspapers) or not (dinner table conversation)" (KRESS; VAN LEEUWEN, 2006, p. 4).
} 
A perspectiva semiótica, em diálogo com as metáforas, com as formas de representação e a ADC, concentra-se em perceber os modos como os recursos semióticos são utilizados no texto multimodal para compreender como a produção de significados ocorre intrinsecamente ligada às escolhas sociais, às marcas políticas, às lutas de poder e, por isso, essa tríade teórica constitui-se balizadora para a análise do texto selecionado.

\section{0 arranjo dos significados no corpus}

O texto escolhido para análise faz parte do jornal "ACapa", publicado no dia 5 de maio de 2016. Esse jornal se descreve como “um jornal sem jornal” e se classifica como "a primeira página que você não vê no jornal que você lê" 5 .

O jornal "ACapa” foi fundado em 23 de março de 2016. Apresenta conteúdo pautado nos acontecimentos atuais da sociedade e, a maior parte deles, com enfoque político, sem abrir mão da criatividade peculiar da expressão visual e também jornalística. Cabe ao leitor inferir conexões entre o conteúdo da capa e a realidade dos noticiários e manchetes de outros jornais.

A opção de análise, dessa maneira, centra-se na construção de significados, permeados pelas metáforas visuais que estão representadas no recorte específico do jornal que foi publicada no Facebook, em 5 de maio de 2016.

A seguir, empreendemos a análise do corpus selecionado, iniciando à luz da Gramática de Design Visual, em seguida, Análise de Discurso Crítica e, por fim, as considerações relacionadas às metáforas da vida cotidiana com enfoque nos significados representacionais, apontados no decorrer da análise.

\footnotetext{
5 O meio de distribuição do jornal “ACapa” são as redes sociais como o Facebook (www.facebook.com/acapabr), Instagram (www.instagram.com/acapabr), $\quad$ Twitter (www.twitter.com/acapabr), Tumblr $\quad$ (www.acapabr.tumblr.com), Pinterest (www.pinterest.com/acapabr), Snapchat (acapabr), Email (acapabr@gmail.com) e Site (http://www.acapabr.tumblr.com).
} 
Análise: 0 que pode ser visto na panela?

Texto 1 - “ACapa”, 5 de maio de 2016

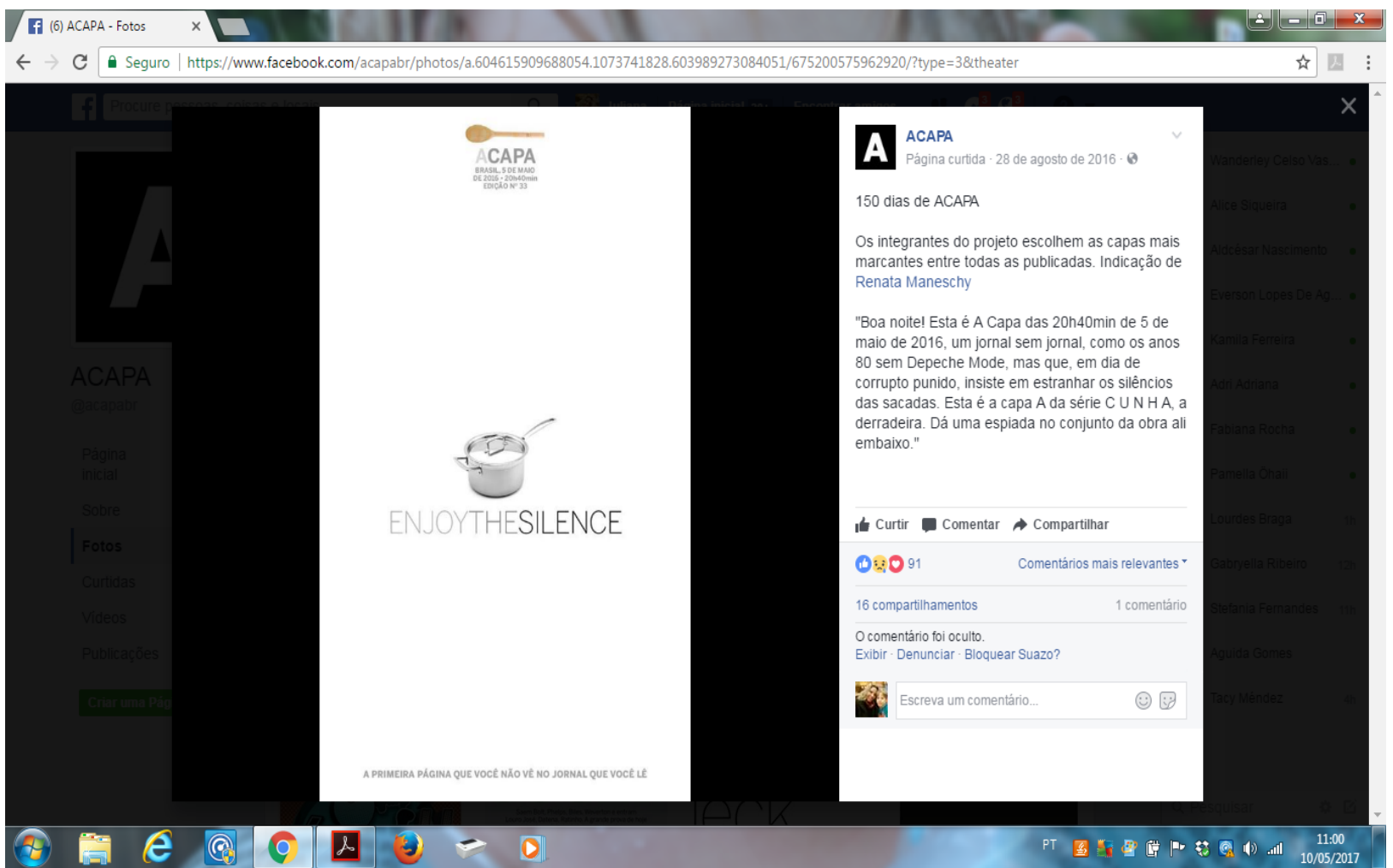

Fonte: https://www.facebook.com/acapabr/photos

À esquerda, há poucas palavras escritas e o destaque foi dado à imagem da panela, objeto comum na sociedade brasileira, utilizado especificamente, até a conjuntura histórica representada no texto, para cocção de alimentos. À direita, o destaque é para o texto verbal transcrito a seguir.

"Boa noite! Esta é ACapa das 20h40min de 5 de maio de 2016, um jornal sem jornal, como os anos 80 sem Depeche Mode, mas que, em dia de corrupto punido, insiste em estranhar os silêncios das sacadas. Esta é a capa A da série $\mathrm{C} U \mathrm{~N} \mathrm{H} \mathrm{A}$, a derradeira. Dá uma espiada no conjunto da obra ali embaixo".

\section{Análise à luz da Gramática do Design Visual}

Iniciamos pelo recorte do texto ilustrativo, especificamente multimodal, o qual foi denominado, com intuito de destaque do tópico, como “circuito visual”. É parte do objeto de análise, apresenta relação de complementariedade entre o texto escrito e a 
imagem centrada na panela que foi entendida por nós como representação metafórica de uma classe social brasileira.

Figura 1 - Circuito visual

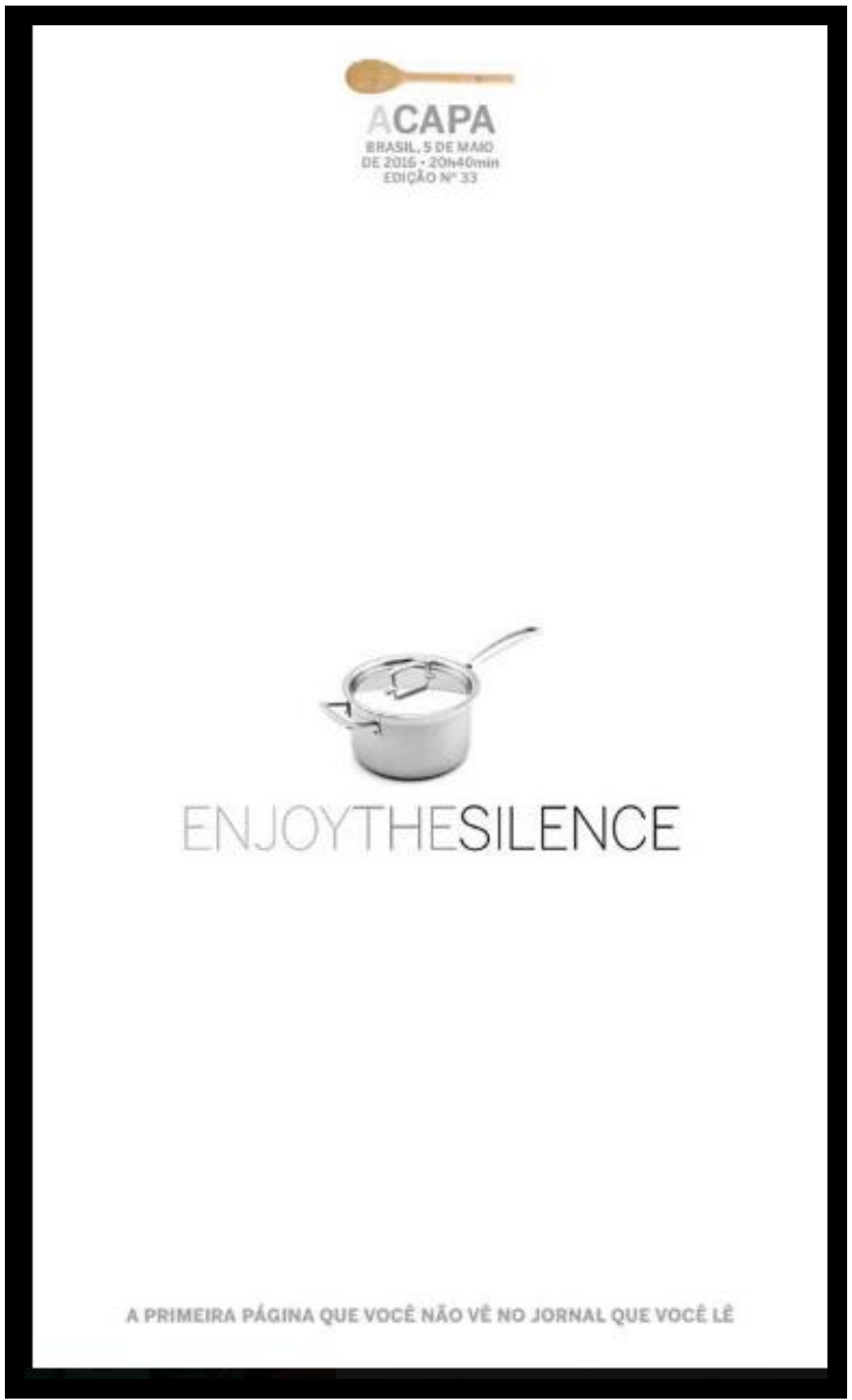

Fonte: https: / /www.facebook.com/acapabr/photos 
No texto da Figura 1, denominado Circuito Visual, observa-se a imagem de uma panela que representa como metáfora da classe média brasileira.

\section{Quanto ao significado representacional}

À luz da GDV, as metafunções realizam suas representações dentro de esquemas específicos. Assim, considerando a metafunção representacional, a exemplo da estrutura linguística, a representação dos participantes, incluindo os "abstratos", em termos de seres, coisas e lugares em interação, envolvidos em processos que trazem significados a serem apreciados como ação e acontecimento e transformação. (KRESS; VAN LEEUWEN, 2006, p. 73).

Portanto, a representação dos participantes, ao lado de outros elementos composicionais e estruturantes como os processos e as circunstâncias, nos textos multimodais, exerce funções léxico-gramaticais com o objetivo de significar o modo semiótico a que se propõem.

Com base nessa concepção, Kress e van Leeuwen (1996, 2006) apontam em termos de estruturas visuais como narrativas e conceituais. As narrativas caracterizamse pela dinamicidade, pois se inserem na experiência material de mundo do fazer e acontecer.

De acordo com os autores, as estruturas narrativas relacionam-se com as ações dos participantes que podem ser coisas ou pessoas e que se caracterizam por estruturas visuais as quais se realizam por meio de processos de ação e de reação, sejam mentais e/ou verbais.

Quanto às estruturas conceituais, elas são estáticas, desprovidas de relações espaciais e direcionais, cujos participantes são representados com significações de forma atributivas e a elas podemos atribuir valores. Situam-se na experiência de ser e de existir no mundo, conforme Kress e van Leeuwen (2006).

O foco está na imagem analisada se estabelece então, nos atributos e identidades dos participantes e suas características se configuram a partir da disposição de sua apresentação em uma relação de parte ou todo e de detalhamento do pano de fundo, cores e do contexto histórico de criação.

Considerando, então, os conceitos de Kress e van Leeuwen, na Figura 1, o participante representado em destaque é uma panela. Essa representação é tipicamente conceitual, pois indica um processo de relação entre a identidade (o que é? E a noção de pertencimento de classe social quem a usa?) que adota tal objeto para 
manifestações políticas (para que a usa?). No caso, pode-se inferir que os atributos do objeto representado estão relacionados à atuação política de certa classe social. A representação ocorre com apenas uma panela tampada e isolada, no centro do texto, nos conduziu ao processamento da interpretação de um posicionamento passivo e enfraquecido, especialmente, nessa data de publicação.

A representação conceitual da panela ocorre por processo simbólico e faz referência ao movimento social denominado panelaço. Os panelaços são manifestações, previamente organizadas, de cunho crítico ao governo e nesse movimento a população, sentindo-se insatisfeita, exige mudanças nas lideranças políticas. Atualmente, as redes sociais são usadas como o principal meio de comunicação para que as pessoas se articulem em manifestações dessa natureza. O texto imagético estabelece uma relação de complementariedade com o texto de apoio escrito que vem na sequência.

\section{Quanto ao significado interacional}

Quanto aos recursos visuais, a metafunção interacional instancia relações entre produtor, produto e observador, podendo ocorrer na forma escritor, texto, leitor, extensivo a todas as formas alusivas à produção e recepção de texto (KRESS; VAN LEEUWEN, 2006).

No desempenho de seu papel, o produtor constrói a representação a ser interpretada pelo leitor que traduz os possíveis significados apresentados pelas imagens, conforme os contextos sociais em que são utilizadas. Assim, as relações de interação significam-se, conforme as realizações visuais, como o contato (oferta ou demanda), a distância social (plano fechado e plano aberto), a perspectiva (frontal, oblíquo e vertical) e valor (natural e sensorial), conforme a GDV de Kress e van Leeuwen (1996, 2006).

A perspectiva frontal e a dimensão reduzida da panela pode indicar uma atitude subjetiva do produtor do texto em relação ao caráter ideológico que estabelece distanciamento do participante representado em relação aos manifestantes que o utilizam.

Há também a possibilidade de observar o cabo da panela que aparece em ângulo oblíquo, no posicionamento diagonal em relação ao leitor. Isso pode ser analisado como a intenção de direcionar o olhar do leitor da direita para a esquerda e de cima para baixo num movimento descendente, tendo em vista que a maior proporção do objeto 
representado, mesmo estático, encontra-se nessa direção. Parece ser um indício de que o movimento panelaço inicia o processo da decadência política do país.

\section{Quanto à composição do texto}

A metafunção composicional, segundo os pressupostos de Kress e van Leeuwen (1996, 2006), descreve a organização espacial dos elementos, observando valores informacionais que podem ser representados pelo recurso do enquadramento, moldura; saliência e projeção, com base no posicionamento dos elementos como esquerda ou direita em uma relação de dado ou novo; topo ou base, em relação ao que é real ou ideal; centro ou margem com relação à informação principal e informação complementar; na relação entre os elementos da imagem como interligadas ou segregadas; nas estratégias para dar maior ou menor destaque a certos elementos como tamanho, cores e posicionamento em primeiro e segundo plano.

No que se refere às categorias composicionais que se apresentam na Figura 1, observa-se que a cor do plano de fundo é o branco e a cor esmaecida, acinzentada da imagem da panela parece revelar certo enfraquecimento da mobilização civil. No centro da moldura está posicionada a imagem destaque da panela, em primeiro plano, por ser a informação principal do evento que idealizou a criação do texto: o panelaço.

Ainda quanto ao posicionamento, a centralidade da panela sugere a metáfora como informação nova e o texto "Enjoy the silence" como a informação dada.

Quanto ao texto escrito, está claro, centralizado ao topo da página, revelando a circunstância de tempo (em maio de 2016) e espaço (Brasil) e é nesse contexto que o evento se desenvolve. O texto "Enjoy the silence" é complementar à imagem e faz referência ao posicionamento político da classe social retratada, complementa a ideia representada pela panela tampada como a classe social silenciada.

Quanto à categoria das cores, observa-se que o enunciado aparece em escala de cinza em tons esmaecidos, denotando enfraquecimento e negligência de qualquer reação da classe social representada diante do evento político situado no texto escrito introdutório.

A escala de cinza do enunciado evolui até a cor preta, dando destaque à palavra "silence". Esse destaque pode ser compreendido como referência e reforço à omissão, à indiferença e à inércia da classe média brasileira naquele momento político. Aqui, observa-se um certo caráter de julgamento subjetivo interpelado pelo produtor do texto que de forma ambígua e irônica questiona posicionamento dos participantes. 


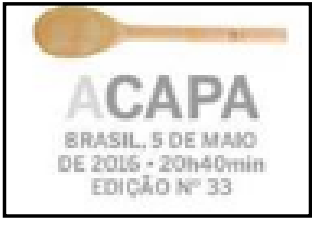

Além disso, a colher e pau que acompanha o nome do jornal, no topo da página, representa a marca dos próprios produtores do texto, o que sugere um protesto por meio da ação de bater a colher nas panelas como forma de manifestar seu descontentamento com a inércia da sociedade brasileira em relação ao contexto social e político do país.

\section{Panelinha social: uma metáfora orientacional}

Lakoff e Johnson (2002) consideram que as metáforas estão diluídas no pensamento e na vida cotidiana e são materializadas por meio da linguagem. De acordo com os autores, a metáfora reproduz algo presente na consciência, duplica sua representação num contexto diferente do usual e recorre à imaginação para estabelecer a relação semiótica entre o fato apresentado e o contexto de apresentação.

A metáfora consiste, então, em uma imagem mental que envolve processos de assimilação do signo que representa o objeto de referência, em uma relação de significação que ocorre entrelaçada ao contexto e que aciona na mente do leitor concepções da realidade.

Sob essa perspectiva, no texto em análise, a representação da panela está para as classes sociais como a simulação de uma relação reflexiva e transitiva da realidade. 0 signo 'panela' remete a uma imagem mental e relaciona o seu conceito ao barulho como aspecto desse signo, o que direciona a relação metafórica entre a panela e determinada classe social brasileira e reporta também ao "panelaço".

0 jornal e a classe média, ambos, se identificam com o movimento do "panelaço", uma vez que a colher de pau corresponde ao jornal. Isso ocorre em um processo de representação mental verbal e visual que é articulado no âmbito discursivo como uma atividade inerente aos textos e discursos sociais.

A apresentação das imagens da panela e da colher de pau não pode servir como meio de reflexão sobre elas mesmas, mas amparam-se no texto verbal para a construção do significado metafórico. Ambos, imagem e texto, estão intrinsecamente ligados numa relação de complementariedade.

Segundo as categorias das metáforas orientacionais listadas por Lakoff e Johnson (2002), a que se relaciona ao texto analisado é "ter controle ou força é para cima; estar sujeito a controle ou força é para baixo". A metáfora estabelecida na imagem sugere força política e controle da situação concentrada na imagem da panela e transfere o poder de decisão para os participantes representados: o jornal e a classe média. 
A opção, portanto, de utilizar, as panelas para fazer barulho como forma de protesto é positivo, é para cima, é a reação que se espera da classe média brasileira. Ou ainda que, tomar para si uma colher de pau como instrumento de provocação é para cima, significa atitude positiva, ao passo que deixar a panela tampada, silenciada é para baixo, significa uma atitude negativa.

\section{0 que tem na panela?}

Toma-se como objeto de análise o seguinte texto introdutório:

“Boa noite! Esta é ACapa das 20h40min de 5 de maio de 2016, um jornal sem jornal, como os anos 80 sem Depeche Mode, mas que, em dia de corrupto punido, insiste em estranhar os silêncios das sacadas. Esta é a capa A da série CUN HA, a derradeira. Dá uma espiada no conjunto da obra ali embaixo."

Figura 2 - Elementos textuais

\section{A} ACAPA

Página curtida - 28 de agosto de 2016 - B

150 dias de ACAPA

Os integrantes do projeto escolhem as capas mais marcantes entre todas as publicadas. Indicação de Renata Maneschy

"Boa noite! Esta é A Capa das 20h40min de 5 de maio de 2016, um jornal sem jornal, como os anos 80 sem Depeche Mode, mas que, em dia de corrupto punido, insiste em estranhar os silêncios das sacadas. Esta é a capa A da série $\mathrm{C} \cup \mathrm{NH} \mathrm{A}$, a derradeira. Dá uma espiada no conjunto da obra ali embaixo."

Fonte: https://www.facebook.com/acapabr/photos

O texto faz referência à Depeche Mode, uma banda inglesa de música eletrônica e rock dos anos 80. A referida banda lançou em 1990 uma música intitulada Enjoy the Silence, um das canções mais bem-sucedidas da banda, no álbum Violator, na qual os autores fazem alusão à trivialidade das palavras. 0 título da música serviu de inspiração para a composição da capa do jornal de 5 de maio de 2016. 
O texto também relaciona a necessidade de um jornal para relatar todos os acontecimentos políticos e sociais do daquele dia. Isso é observado na expressão "um jornal sem jornal, como os anos 80, sem Depeche Mode".

Além disso, o texto faz alusão ao contexto político, no qual o deputado federal Eduardo Cunha que foi afastado do cargo de Presidente da Câmara pelo Superior Tribunal Federal por ser réu em uma ação penal com o trecho "esta é a capa da série CUNHA". Ainda com a expressão “em dia de corrupto punido", o texto sugere a possível condenação de Cunha na ação penal em que, naquele momento, ainda era julgado.

O jornal, nessa produção, evoca também o movimento “panelaço” direcionando sua convocação às "sacadas” no trecho “insiste em estranhar os silêncios das sacadas”.

\section{O olhar da Análise de Discurso Crítica}

Para os estudos do discurso, Fairclough (2001) explica que uma abordagem discursiva crítica pauta não só na descrição da prática discursiva, mas também ao mostrar como o discurso é moldado por relações de poder e ideologias e os efeitos construtivos que o discurso exerce sobre as identidades sociais, as relações sociais e os sistemas de conhecimento e de crença.

Nessa perspectiva, o jornal faz uso da intertextualidade e evoca termos de uso em outros meios sociais como em manifestação popular, estabelecendo uma interação entre o jornal e a classe média na medida em que os representa como uma panela esmaecida e tampada, metáfora para a classe média brasileira e uma colher de pau como a logomarca do jornal.

O termo intertextualidade foi aplicado por Fairclough (2001, p. 133) para assegurar a sua potencialidade para a ADC, pois, segundo o autor, "não há enunciado que de maneira ou de outra não reatualize outros” e, é dessa forma que ocorre a reestrutura de convenções existentes como o caso da "panela".

0 texto multimodal, mediado pelas redes sociais, com a característica apresentada pelos editores de “ACapa” implica uma criteriosa seleção dos leitores que terão acesso aos significados do conteúdo. Isso ocorre não só pelo meio de veiculação do jornal, mas também pelas referências e inferências sugeridas pela composição dos textos. Como por exemplo, a menção à banda Depeche Mode e às sacadas vazias.

Essa pode ser considerada uma estratégia discursiva que seleciona o perfil do leitor que poderá ter amplo acesso à informação e aos processos de significação do texto. 0 posicionamento indica a disposição política e ideológica dos produtores do 
texto e marginaliza os leitores e cidadãos que não têm acesso ou que discordam desse ponto de vista, pois insinua certo empoderamento da classe média e da mídia.

Sob a ótica dos estudos do discurso, o evento social representado é o "panelaço" no qual os participantes mostram-se ora em posição passiva quando retratados pela panela tampada e silenciada, ora como ativos quando reproduzidos pela colher de pau que incita uma provocação.

Esses atributos reforçam uma significação social e ideológica estável no contexto histórico no qual as manifestações populares de oposição ao governo se mostram bastante polarizadas e conduzem à inferência de uma luta de classes e, por vezes, parecem um tanto manipuladas pela mídia. São manifestações que se pode questionar a legitimação enquanto ato político consciente e direcionado. É como se os participantes não tivessem dimensão da real motivação e envolvimento com a realidade política do país. Esta incongruência está de acordo com o que pensam Machin e van Leeuwen (2007) ao afirmarem que as mensagens refletem as diferenças, as incongruências e os embates presentes na sociedade.

Ainda, com base na ADC, Ramalho e Resende (2011, p. 51) elucidam que são "estilos, maneiras de identificar a si e aos outros, pressupõem identidades sociais $e$ individuais".

No encadeamento do texto, os atores sociais são representados por uma panela tampada e uma colher de pau como forma de recontextualizar a negligência da classe média no que se refere à circunstância política do país e a provocação que o jornal faz a esta classe.

A metáfora da panela delineia o perfil de identidade dos participantes, e também instiga a reflexão sobre a coerência entre as articulações das manifestações populares. Essas identidades dependem do contexto e influem uma oposição na sociedade na qual de um lado é considerado um grupo de nível elevado de empoderamento e consciência política e de outro está o grupo marginalizado. Tal posicionamento pode tornar a diversidade completamente invisível e pode ser um julgamento falho, na medida em que aponta apenas um ponto de vista, uma única categoria capaz de resolver o problema, o que segrega e exclui os cidadãos que não fazem parte da classe social representada, demandando, assim, práticas sociais de poder.

Sob o ponto de vista da produção e distribuição do texto, este foi institucionalmente organizado por um editor e por jornalistas colaboradores do jornal que definem estratégias e meios de consumo do texto, utilizando signos e significados 
culturalmente envolvidos e constituídos por meio de composições de conotação, metáforas e ironias. Então esse é um texto para fins de consumo por certa condição de leitores.

São textos criados e propagados para servir a interesses e necessidades de poder e/ou empoderamento de instituições sociais. No entanto, há que se intuir qual foi o interesse e para que serve esta forma de representação em textos.

Consideramos que textos como esse trazem informações que tem consequências materiais e políticas, pois instrumentalizam mobilizações, e fazem provocações, além de sugerir uma identificação do leitor com o estrato social representado.

\section{E por falar em panelas... algumas considerações}

As publicações midiáticas fazem frequente uso de textos multimodais e para compreendê-las é preciso articular e interpretar a conjunção dos diversos modos semióticos que o texto apresenta com as condições de produção e situá-las no contexto social, histórico e político.

Os significados operam simultaneamente, nos textos multimodais, indicando padrões de experiência, interação social e posições ideológicas imbricadas nas escolhas acerca da realidade que é representada. O modo como essas representações se constituem no plano verbal e visual costuma ser permeado de metáforas as quais contribuem para a construção de identidades sociais.

Dessa forma, os recursos semióticos utilizados no corpus analisado induzem aos processos ideológicos de poder, evidenciando um contexto de manifestação política, tanto dos produtores do texto quanto dos receptores. Este poder foi observado na articulação das metáforas com as representações imagéticas e linguístico-discursivas em um contexto social e político numa relação de complementaridade e de significados.

Embora os produtores do texto, ao optarem pela panela tampada e qualificarem os participantes por meio do enunciado "enjoy the silence", insinuem passividade, o contexto de significação, tanto da metáfora visual, quanto do texto escrito, evoca o movimento de manifestação. Assim, foi possível observar uma ambuiguidade de significação, pois uma evocação pode motivar indivíduos simpatizantes das mesmas crenças e comportamentos, elaborados com posicionamentos políticos semelhantes a aderirem ao "panelaço". O jornal, entretanto, põe em questionamento a inércia dos representados pela panela tampada e com base nesse entendimento, pode ocorrer a dúvida sobre em quem recai a responsabilidade e o controle da manifestação. Sobre a 
classe média retratada pela panela ou sobre a imprensa representada pela colher de pau, ou, ainda, por ambas.

Nesse processo, uma determinada classe social, caracterizada pelo seu poder econômico, é colocada em evidência, em detrimento das demais classes sociais, o que pode ser qualificado um modo de exclusão de parte dos compõem a sociedade civil como aqueles que leem esse tipo de texto e os que não leem o jornal “Acapa”.

\section{Referências}

ACAPABR. Disponível em: <http://www.facebook.com.br/acapabr>. Acesso em 16 e maio. 2016.

BATISTA, E. A. Identidades de docentes brasileiros e suas representações discursivas em charges. 191 f. Tese de Doutorado em Linguística, Universidade de Brasília (UnB), Brasília. 2014.

BRASILEIRO, A. M. M. Manual de produção de textos acadêmicos e científicos. São Paulo: Atlas, 2013.

FAIRCLOUGH, N. Analysing discourse: textual analysis for social research. London, New York: Routledge, 2003.

FAIRCLOUGH, N. Discurso e mudança social. Tradução de Izabel Magalhães. Brasília: Editora Universidade de Brasília- UnB, [1992], 2001.

HALLIDAY, M. A. K. Language as Social Semiotic: the social interpretation of language and meaning. London: Arnold, 1994.

HODGE, R.; KRESS, G. Social Semiotics. London: Polity Press, 1988.

KRESS, G.; VAN LEEUWEN, T. Reading images: the grammar of visual design. London: Routledge, [1996] 2006.

KRESS, G. Multimodality: A Social Semiotic Approach to Contemporary Communication. New York: Routledge, 2010.

LAKOFF, G.; JOHNSON, M. Metáforas da vida cotidiana. São Paulo: Mercado de Letras, 2002.

MACHIN, D.; van LEEUWEN, T. Global genres. In: MACHIN, D.; van LEEUWEN, T. Global Media Discourse: a critical introduction. London and New York: Routledge, 2007. NEVES, J. L. Pesquisa qualitativa - caracteríticas, usos e possibilidades. Cadernos de Pesquisa em Administração. São Paulo. V. 1, n. 1, 2. Semester, 1996.

RAMALHO, V.; RESENDE V. M. Análise de discurso (para a) crítica: o texto como material de pesquisa. São Paulo, Campinas: Contexto, 2011. 
SANTAELLA, L.; NOTH, W. Imagem como representação visual e mental. In: SANTAELLA, L.; NOTH, W. Imagem: cognição, semiótica, mídia. São Paulo: Iluminuras, 2014.

VAN LEEUWEN, T. A representação dos atores socias In: PEDRO, E. R. Análise Crítica do Discurso: uma perspectiva sociopolítica funcional. Lisboa: Caminho, 1997.

VIEIRA, J. A.; FERRAZ, J. A. Percursos e avanços do texto multimodal: novas perspectivas na contemporaneidade. In: Discursos Contemporâneos em Estudo v.1, n.1. 2011. 
